\title{
Calculation and experimental technique for evaluating the parameters of the contact interaction of a strip billet with a roll tool in the ERW mill lines
}

\author{
S. V. Samusev, Dr. Eng., Prof., Metal Forming Dept. ${ }^{1}$ \\ V. A. Fadeev, Post-Graduate, Metal Forming Dept. ${ }^{1}$, e-mail:fdv_viktor@mail.ru \\ A. S. Budnikov, Cand. Eng., Associate Prof., Metal Forming Dept. ${ }^{1}$ \\ M. B. Savonkin, Cand. Eng., Associate Prof., Metal Forming Dept. ${ }^{1}$
}

${ }^{1}$ National University of Science and Technology "MISiS”, Moscow, Russia

\begin{abstract}
A technique for determining the areas of contact surfaces for the lower and upper roll tools is presented. The study of contact surfaces was carried out on contact prints obtained as a result of the experiment. The drawbacks of the existing method of fixing the imprints of contact surfaces, in which the contact of the strip (tubular billet) with the rolls was determined through the paper, were analyzed and taken into account. A technique for fixing contact prints is proposed, in which there is a direct contact of the strip with the rolls. Parameters of the obtained contact prints of the strip with the lower and upper rolls for all forming stands electric of ERW mill 30-50 were measured. As a result of measurements of contact prints, additional parameters of the boundaries of contact surfaces are introduced. For the bottom and top rolls, the length of the contact was taken along the bottom and the flange of the roll, respectively. It was found that, in the first approximation, the contact surfaces can be rather exactly approximated by a power function. The internal contact surfaces of the strip with the upper rolls were approximated using a decreasing power function, while the external ones with the lower rolls - using an increasing power function. On the basis of experimental data and analysis of indentation parameters, a technique has been developed for determining the contact surfaces of a strip with lower and upper rolls of various configurations. The input boundary of the contact surface was determined by the shape index $\mathrm{m}$. Comparison of the input boundaries of the contact surfaces obtained in the experiment and by the technique shows a high convergence.

Key words: electric welded pipe, continuous forming, roll forming, pipe, ERW mill, contact surface, contact area, forming mill.
\end{abstract}

DOI: $10.17580 /$ cisisr.2021.02.06

\section{Introduction}

It's known that different technological lines for manufacture of electric resistance-welded pipes are used in ERW production [1-5]. The area for forming of initial flat tubular billet with consequent manufacture of finished pipe is mainly the feature of such technological lines [6, 7]. Different deformation tools and forming routes are used depending on dimension range of pipes. Combination of roll tools and choosing kinematic and power parameters should provide stable strip billet forming in the steady deformation area [8-13]. To achieve stable forming process, it is necessary to determine such contact interaction and contact area between deformation tool and strip billet, when metal forming at the contact surfaces is carried out and all required process technical parameters are calculated [14-19]. Thereby, the contact interaction between tubular billet and deformation tool should be examined. Interaction of a tubular billet with deformation tool is a decisive factor in determination of power and kinematic parameters of tubular billet forming process [20-22]. This interaction occurs along the contact surfaces, where controlled variation of tubular billet geometrical parameters and all technical parameters takes place. These contact surfaces were determined by boundaries and contact area between strip and roll tool, they can be examined on the obtained contact prints. Determination of contact surfaces is the main task for determination of power parameters during forming process.

The work [23] presents the technique for calculation of contact surfaces based on the contact prints. These prints were obtained during deceleration of a forming strip in the forming stands, with paper gluing on strip, applying graphite powder on rolls, consequent switching-on the rolling mill and forming until the strip sections with paper will enter the passes. Then forming was stopped, rolls were moved apart, tubular billet was extracted with paper having the prints of contact surfaces. Such method of obtaining the contact prints can have the effect on the results, because the contact between strip and rolls was determined using graphite powder and paper. The obtained boundaries along the width of the contact surface look like bows, but to calculate the square, these bows were mainly replaced by chords, while the contact surfaces were taken as triangles [23]; however, the strip contact lengths along the bottom of lower rolls and along the rib with upper rolls were not taken into account. This method of contact surfaces square calculation is suitable for assessment calculations, but it is not sufficient for analysis of strip forming power and kinematic parameters in the processes of real forming at the operating ESR mills. The technique excluding use of any remedies (graphite, paper) which make obstacles for direct contact between strip and rolls is suggested in the work [24]. 


\begin{tabular}{|c|c|c|c|c|c|c|}
\hline \multicolumn{6}{|c|}{ Table 1. Parameters of the input strip contact prints } \\
\hline \multirow{2}{*}{ No. } & \multicolumn{3}{|c|}{ Upper roll } & \multicolumn{3}{c|}{ Lower roll } \\
\cline { 2 - 7 } & $\mathrm{b} / 2, \mathrm{~mm}$ & $\mathrm{~L}_{\mathrm{ub}}^{\mathrm{i}}, \mathrm{mm}$ & $\mathrm{L}_{\mathrm{ur}}^{\mathrm{i}}, \mathrm{mm}$ & $\mathrm{b} / 2, \mathrm{~mm}$ & $\mathrm{~L}_{\mathrm{lb}}^{\mathrm{i}}, \mathrm{mm}$ & $\mathrm{L}_{\mathrm{lr}}^{\mathrm{i}}, \mathrm{mm}$ \\
\hline 1.OP & 80.5 & 2.6 & 1.5 & 80.5 & 3.0 & 23.6 \\
\hline 2.OP & 80.5 & 3,0 & 1.6 & 80.5 & 3.0 & 26.7 \\
\hline $3 . \mathrm{OP}$ & 50.1 & 3.6 & 2.4 & 72.3 & 3.0 & 29.5 \\
\hline $4 . \mathrm{OP}$ & 21.7 & 4.0 & 2.0 & 52.1 & 3,0 & 29.9 \\
\hline 1.CP & 48.6 & 3.0 & 23.25 & 32.6 & 5,0 & 22.98 \\
\hline 2.CP & 44.4 & 3.0 & 21.87 & 35.8 & 4,0 & 22.25 \\
\hline 3.CP & 43.7 & 3.0 & 20.51 & 38.8 & 4.0 & 21.33 \\
\hline Remayyyyyy &
\end{tabular}

Remark: 1.OP; 2.OP; 3.OP; 4.OP - first, second, third and fourth open passes; 1.CP; 2.CP; 3.CP - first, second, third and fourth closed passes; $\mathrm{b} / 2$ - half of the contact print width

Therefore, we have wide range of roll tools and forming routes. Now we need to add both theoretical and experimental investigations about the processes of contact interaction. Conduction of the new experiments for fixing the contact surfaces and development of the new techniques for determination of contact surfaces squares between strip billet and roll tools is now the actual problem.

The aim of this work is to examine the contact interaction between strip billet and roll tools on the base of calculated and experimental data and to develop the technique for square determination of contact surfaces.

The calculation technique for strip contact surfaces with shaped rolls includes the principal aspect of determining profiles parameters. The routes of strip contact surfaces in a roll pass are presented on the Fig. 1. According to this route, the strip contact surface with the lower roll (I) is determined by the following parameters: the contact strip line along the lower roll rib $L_{l r}^{i}(2)$, the strip contact input boundary with the lower roll (3), the contact strip line along the bottom of the lower roll $L_{l b}^{i}$ (4). The strip contact surface with the upper roll (5) is determined by the following parameters: the strip contact input boundary with the lower roll (6), the contact strip line along the upper roll bottom $L_{u b}^{i}(7)$, the contact strip line along the rib of the upper roll $L_{u r}^{i}(8)$.

\section{Description of the experiment on fixing strip contact surfaces with rolls}

The contact surfaces of the tube $50 \times 1.5 \mathrm{~mm}$ were examined in the conditions of ERW mill 30-50 in the scientific and production center of the Metal forming department at the National University of Science and Technology "MISiS". The tubular billet was retarded in forming stands, while dye was applied on external and internal surfaces of the strip located in the passes of forming stands. Then the rolls were moved apart and the tubular billet was extracted with obtained contact prints which include input and exit areas $[24,25]$.

The measuring results for parameters of the contact prints were presented in the Table $\mathbf{1}$.

The suggested calculation technique for strip contact surfaces takes into account the contact length along the bot-

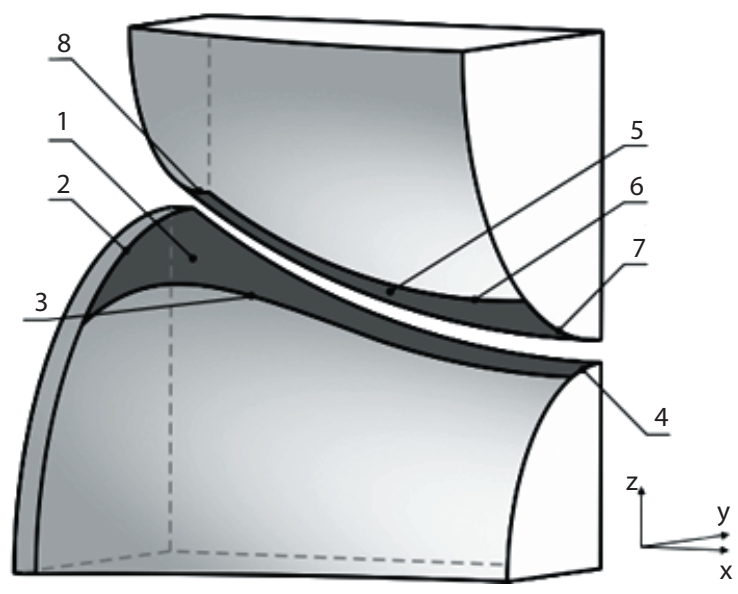

Fig. 1. Roll pass with strip contact surfaces (tubular billet): $1-$ strip contact surface with the lower roll; 2 - contact strip line along the lower roll rib $\left(L_{l r}^{i}\right) ; 3$ - strip contact input boundary with the lower roll; 4 - contact strip line along the bottom of the lower roll $\left(L_{l b}^{i}\right) ; 5$ - strip contact surface with the upper roll; 6 - strip contact surface with the upper roll; 7 - contact strip line along the upper roll bottom $\left(L_{u b}^{i}\right) ; 8-$ contact strip line along the rib of the upper roll ( $\left.L_{u r}^{i}\right)$.

tom with the lower roll ( $L_{l b}^{i}$ ) and the contact length along the rib with the upper roll $\left(L_{u r}^{i}\right)$.

Processing of measured results for contact prints of forming strip with lower and upper rolls shows that the input boundaries restricting the contact surfaces at the entrance of forming strip in a pass can be approximated rather exactly by degree function with exponent of the power $\mathrm{m} \geq 1$ and base of the power varying within 0.1 .

Internal and external strip contact surfaces with the upper and lower rolls respectively can be approximated using correspondingly decreasing or increasing exponent functions (see Fig. $2 \boldsymbol{a}$ and $\mathbf{2 b}$ ).

\section{Technique of determination of the contact area between strip and upper roll}

The contact surface and scheme for determination of boundaries of the contact area between strip and upper roll are presented on the Fig. 3.

General sight of approximating expression for the upper contact surface is presented as

$$
l(b)=L-A\left(\frac{b}{C}\right)^{m}
$$

Numerical constants $A, C, L$ are calculated via experimental values in the center and edge of strip in the following way. The constant $C$ is considered as equal to the maximal half-width of surface contact with the upper damping tool, i. e.

$$
C=b_{1}
$$

Determination of the constants $A$ and $L$ is chosen based on the contact length values along the bottom of the upper roll (this length corresponds the central fiber $l_{0}$ ) and the rib of 


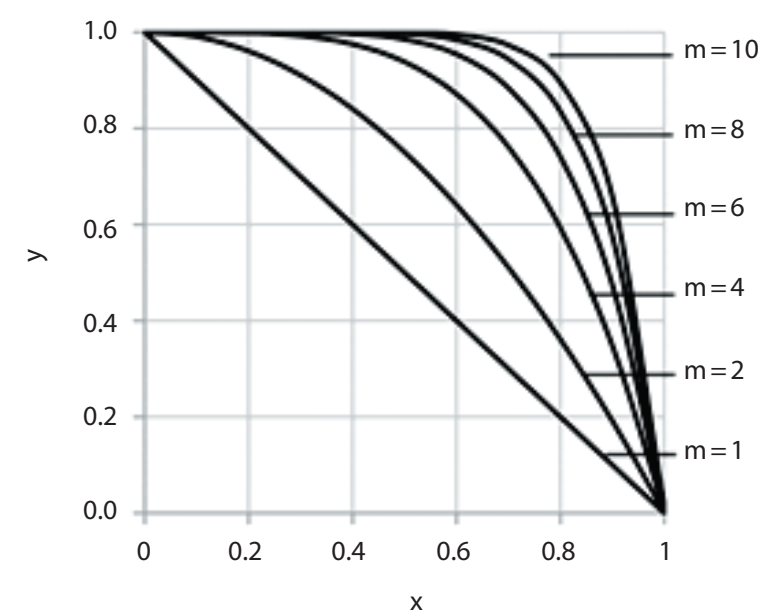

a)

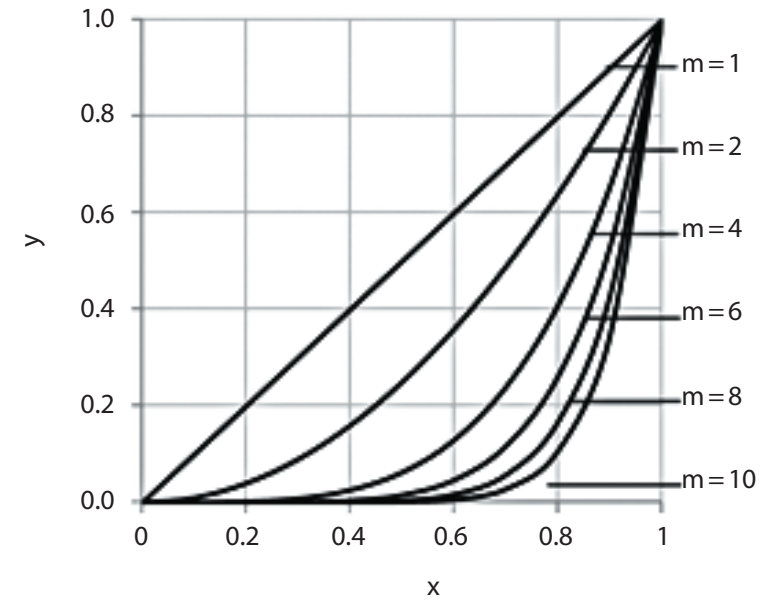

b)

Fig. 2. Analytical description of the input strip boundaries with rolls: $a-$ upper roll; $b-$ lower roll

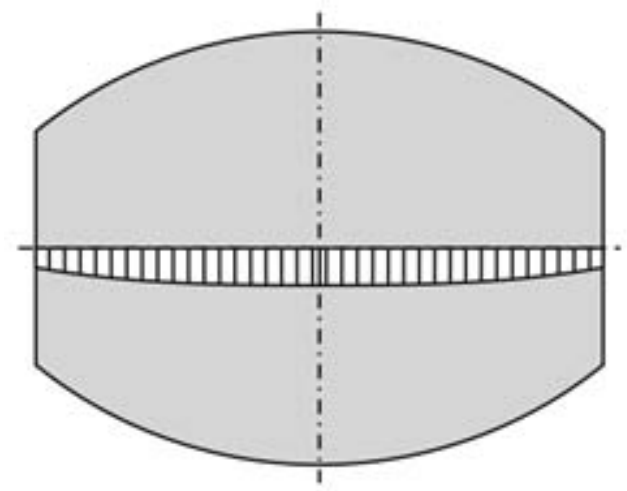

a)

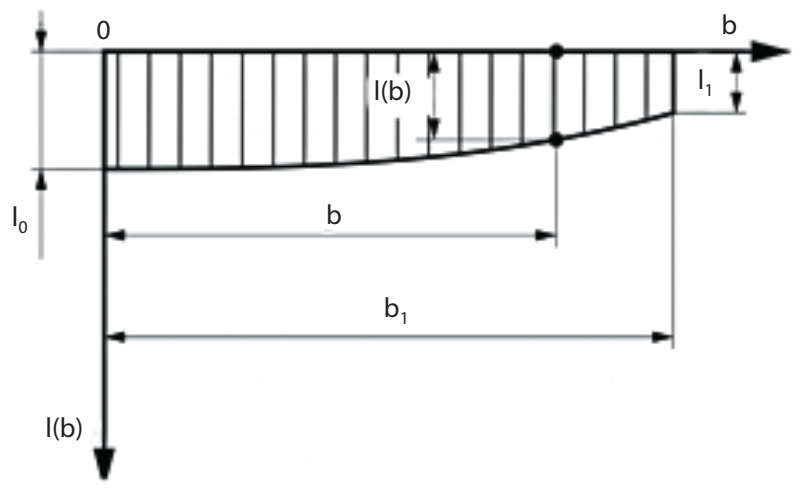

b)

Fig. 3. The contact surface $(a)$ and scheme for determination of boundaries of the contact area between strip (b) and upper roll $(1 / 2$ of the contact surface is presented)

lower roll $l_{1}$ (which corresponds to the strip edge fiber in the complete coverage passes and to the rib edge of the upper roll in the incomplete coverage passes).

$$
L=l_{0} \text { and } A=l_{1}-l_{0}
$$

i.e. we have the following expression for the upper rolls, which gives the exact data of contact length in the strip center and on its ribs

$$
l(b)=\left(l_{1}-l_{0}\right)\left(\frac{b}{b_{1}}\right)^{m}+l_{0}
$$

Exponent of the power $m$ determines the form of the contact surface in correspondence with the graph of increasing exponent function. Exponent of the power $m$ is a shape factor. It can be found via calculation of the mean-square deviation between the experimental and approximated values

$$
\Delta_{i}=\sqrt{\left(l_{i}-l_{i}^{\exp }\right)^{2}}
$$

where $L_{i}^{\text {exp }}$ - the length obtained during the experiment.

The obtained deviations are summarized along all points where the pilot values are known. The required value of the shape factor $\mathrm{m}$ can be found from the minimum condition of the expression

$$
\sum_{i=1}^{N} \Delta_{i}=\frac{1}{N} \sum_{i=1}^{N} \sqrt{\left(l_{i}-l_{i}^{e x p}\right)^{2}}
$$

Calculation of the complete contact square of a tubular billet with upper roll is determined

$$
F_{u}\left(B_{s q}\right)=\left(L_{u b}-\frac{L_{u b}-L_{u r}}{m+1}\right) \cdot B_{s q}
$$

where $L_{u r}-$ length along the rib of the upper roll; $L_{u b}-$ length along the bottom of the upper roll; $B_{s q}$ - width of the upper contact surface; $m$ - shape factor for the input contact with upper roll.

Square of the contact surface between tubular billet and upper roll depends on location $L\left(b_{i}\right)$ along the width of the lower contact surface is determined as

$$
F_{u}\left(b_{i}\right)=L_{u b}-\left(\frac{L_{u b}-L_{u r}}{m+1}\right) \cdot\left(\frac{b_{1}}{B_{s q}}\right)^{m}
$$




\section{Technique of determination of the contact area between strip and lower roll}

The contact surface and scheme for determination of boundaries of the contact area between strip and lower roll are presented on the Fig. 4.

General sight of approximating expression for the lower contact surface is presented as

$$
l(b)=A\left(\frac{b}{C}\right)^{m}+L
$$

Numerical constants $A, C, L$ are calculated via experimental values in the center and edge of strip in the following way. The constant $C$ is considered as equal to the maximal half-width of surface contact with the lower damping tool, i. e.

$$
C=b_{1}
$$

Determination of the constants $A$ and $L$ is chosen based on the contact length values along the bottom of the lower roll (this length corresponds the central fiber 10) and the rib of lower roll 11 (which corresponds to the strip edge fiber in the complete coverage passes and to the rib edge of the lower roll in the incomplete coverage passes).

$$
L=l_{0} \text { and } A=l_{1}-l_{0}
$$

i. e. we have the following expression for the lower rolls, which gives the exact data of contact length in the strip center and on its ribs

$$
l(b)=\left(l_{1}-l_{0}\right)\left(\frac{b}{b_{1}}\right)^{m}+l_{0}
$$

Calculation of the complete contact square of a tubular billet with lower roll is determined

$$
F_{L}\left(B_{c n}\right)=\left[\left(\frac{L_{l r}+L_{l b}}{m+1}\right)+L_{l b}\right] \cdot B_{c n}
$$

where $L_{l r}-$ length along the rib of the lower roll; $L_{l b}-$ length along the bottom of the lower roll; $B_{c n}$ - width of the upper contact surface; $m$ - shape factor for the input contact with upper roll.

Square of the contact surface between tubular billet and lower roll depends on location $L\left(b_{i}\right)$ along the width of the lower contact surface is determined as

$$
F_{L}\left(b_{i}\right)=\left[\left(\frac{L_{l r}+L_{l b}}{m+1}\right) \cdot\left(\frac{b_{i}}{B_{c n}}\right)^{m}+L_{l b}\right] \cdot b_{i}
$$

Calculation results for the shape factor $(\mathrm{m})$ of the profiles and squares of contact surfaces $\left(F_{u}\left(B_{s q}\right), F_{l}\left(B_{c n}\right)\right)$ as well as mean-square deviation $(S)$ are presented in the Table 2.
The contact strip surfaces with the lower and upper rolls for the first forming stand are displayed on the Fig. $5(1 / 2$ of the contact surface is presented). Comparison of input boundary values obtained in the experiment (1) and via the technique (2) shows high convergence.

\begin{tabular}{|c|c|c|c|c|c|c|}
\hline \multicolumn{2}{|c|}{ Table 2. Parameters of strip contact surfaces } \\
\hline & \multicolumn{3}{|c|}{ Upper roll } & \multicolumn{3}{c|}{ Lower roll } \\
\cline { 2 - 7 } & $\mathrm{m}$ & $\mathrm{F}_{\mathrm{u}}\left(\mathrm{B}_{\mathrm{sq}}\right), \mathrm{mm}$ & $\mathrm{S}$ & $\mathrm{m}$ & $\mathrm{F}_{\mathrm{I}}\left(\mathrm{B}_{\mathrm{cn}}\right), \mathrm{mm}$ & $\mathrm{S}$ \\
\hline $\begin{array}{c}\text { 1. Open } \\
\text { pass }\end{array}$ & 2.7 & 364.1 & 0.016 & 8.1 & 842.9 & 0.709 \\
\hline $\begin{array}{c}\text { 2. Open } \\
\text { pass }\end{array}$ & 2.8 & 421.1 & 0.044 & 4.8 & 1133.1 & 0.468 \\
\hline $\begin{array}{c}\text { 3. Open } \\
\text { pass }\end{array}$ & 1.7 & 316.6 & 0.016 & 5.4 & 1032.2 & 0.993 \\
\hline $\begin{array}{c}4 . \text { Open } \\
\text { pass }\end{array}$ & 1.8 & 141.2 & 0.045 & 3.6 & 923.5 & 0.437 \\
\hline $\begin{array}{c}\text { 1. Closed } \\
\text { pass }\end{array}$ & 7.1 & 527.9 & 0.350 & 6.2 & 564.9 & 0.418 \\
\hline $\begin{array}{c}\text { 2. Closed } \\
\text { pass }\end{array}$ & 4.5 & 524.4 & 0.442 & 4.9 & 550.4 & 0.425 \\
\hline $\begin{array}{c}\text { 3. Closed } \\
\text { pass }\end{array}$ & 3.7 & 520.4 & 0.358 & 4.5 & 540.4 & 0.278 \\
\hline
\end{tabular}

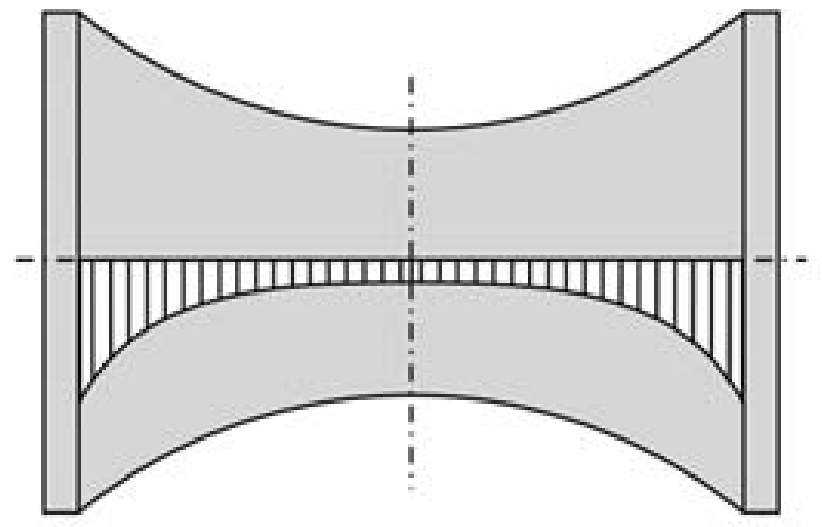

a)

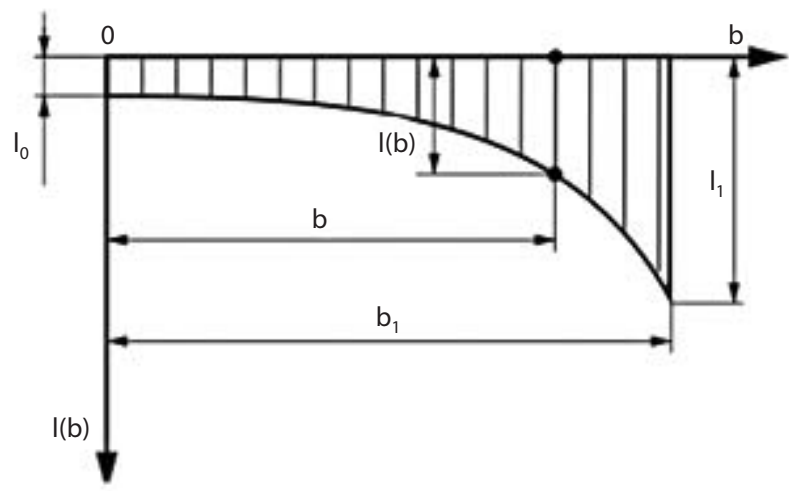

b)

Fig. 4. The contact surface $(a)$ and scheme for determination of boundaries of the contact area between strip (b) and lower roll ( $1 / 2$ of the contact surface is presented) 
Contact width $(\mathrm{b} / 2), \mathrm{mm}$

$0 \quad 5101520253035404550556065707580$

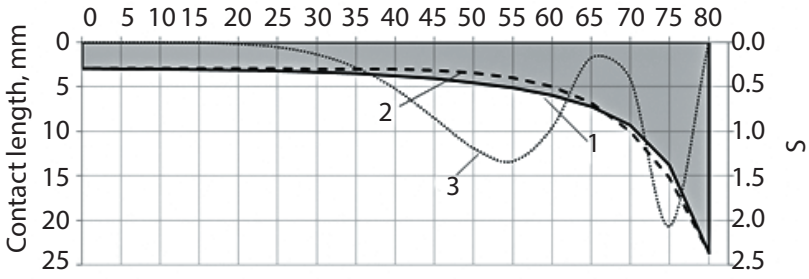

a)
Contact width (b/2), $\mathrm{mm}$

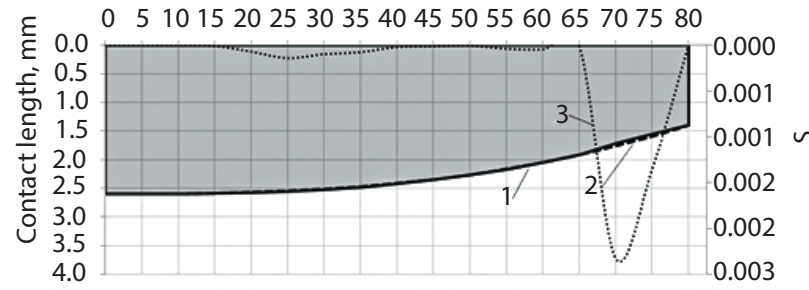

b)

Fig. 5. The contact strip surfaces with the lower ( $\boldsymbol{a}$ ) and upper (b) rolls: $1-$ obtained via the experiment; $2-$ obtained via the technique; 3 - mean-square deviation $\mathrm{S}$

\section{Conclusions}

The experimental technique for calculation and assessment of parameters during contact interaction between strip and roll tool is developed. It allows to determine the boundaries on input contact with different form. Internal contact strip surfaces with the upper and lower rolls are determined by decreasing and increasing exponent functions respectively. The input contact surface boundary was defined by the shape factor $\mathrm{m}$. The technique was applied in determination of contact surfaces square for all passes of the forming ERW mill 30-50. It can be adapted for roll tool with different pass design and construction of ERW mills for small and medium dimension range of products. Comparison of input boundaries for contact surfaces obtained during the experiment and via the technique displays their high convergence.

\section{REFERENCES}

1. Kolikov A. P., Zvonarev D. Yu., Taupek I. M., Sidorova T. Yu. Mathematical simulation of strip plastic deformation process in the whole technological stage of manufacture of large-diameter tubes. Chernye Metally. 2017. No. 7. pp. 41-45.

2. Odesskiy P. D., Gurov S. V., Arsenkin A. M., Gizatullin A. B., Bragin A. A., Titkin A. A. Electric resistance longitudinal-welded highstrength tubes for responsible building constructions. Stal. 2016. No. 7. pp. 73-81.

3. Lifanov V. Ya. Tube industru today and tomorrow. Materials of 23rd International Scientific-Practical conference "Tubes-2018". Chernye metally. 2018. No. 12. pp. 78-81.

4. Ilyichev V. G. Efficiency of modern production technologies and quality of large-diameter pipes. Chernye metally. 2019. No. 9. pp. 17-24.

5. Zhigulev G. P., Skripalenko M. N., Fadeev V. A. et al. Correction to: Modeling of deformation zone during plate stock molding in three-roll plate bending machine. Metallurgist. 2020. Vol. 64. p. 848 (2020). DOI: $10.1007 / \mathrm{s} 11015-020-01062-0$.

6. Kolikov A. P., Zvonarev D. Yu., Taupek I. M. Modeling of the stressstrain state of a metal during plastic forming of a sheet blank and welding of large diameter pipes. Report 1. Chernye Metally. 2020. No. 2. pp. $33-40$

7. Frunkin D., Gurevich L., Novikov R., Bannikov A., Serov A., Dyatlov $\mathrm{N}$. Welded pipe geometry changing during the expanding process. $I O P$ Conference Series: Materials Science and Engineering. 2018. 450. 032048. DOI: $10.1088 / 1757-899 X / 450 / 3 / 032048$.

8. Jiaojiao Cheng, Jianguo Cao, Jianwei Zhao, Jiang Liu, Rongguo Zhao, Shiquan Liu. The flower pattern and rolls design for ERW pipes with the different specification in the flexible roll forming process. Thin-Walled Structures. 2020. Vol. 154. No. 106809. DOI: 10.1016/j. tws.2020.106809.

9. Tovmasyan M. A., Samusev S. V. Effect of the Nonuniform Distribution of the Mechanical Properties of Rolled Sheets on the Shape of a
Round Billet after Forming in Making Large-Diameter Pipes. Russ. Russian Metallurgy (Metally). 2020. pp. 589-596. DOI: 10.1134/ S0036029520050158

10. Shinkin V. N. Analytical calculation of steel billet's shape at production of large diameter pipes on presses of TESA 1020. Chernye metally. 2020. No. 3. pp. 31-35.

11. Li J. -X., Xie L. -Y., Wang J. -J. et al. Numerical study of the forming process of high frequency welded pipe. J. Shanghai Jiaotong Univ. (Sci.). 2010. Vol. 15. pp. 236-240. DOI: 10.1007/s12204-010-8131-9.

12. Kasaei M. M., Moslemi Naeini H., Salmani Tehrani M., Azizi Tafti R. Numerical and experimental investigation of strip deformation in cage roll forming process for pipes with low ratio of thickness/diameter. $A I P$ Conference Proceedings. 2010. Vol. 1315. pp.593-598.

13. Kadach M. V., Gamin Yu. V., Solonin A. N. et al. Converting highboron steel pipe from round to hexagonal cross section. Steel in Translation. 2014. Vol. 44. pp. 783-786. DOI: 10.3103/S0967091214110084.

14. Goncharuk A. V., Gamin Y. V., Sharafanenko I. K. et al. Piercing of a Billet in a Mill with Guide Disks. Russian Metallurgy (Metally). 2020. pp. 1637-1642. DOI: 10.1134/S003602952013011X.

15. Kadach M. V., Koshmin A. N., Gamin Y. V., Romantsev B. A. Obtaining steel tubular items of variable cross-section along their length. Chernye Metally. 2019. No. 4. pp. 37-41.

16. Malakhov A. Y., Saikov I. V., Denisov I. V. et al. Study of the Features of Obtaining Bimetallic Pipes and Rods by Explosion Welding with Subsequent Hot Deformation. Inorg. Mater. Appl. Res. 2020. Vol. 11. pp. 1222-1228. DOI: 10.1134/S2075113320050202.

17. Abeyrathna B., Rolfe B., Hodgson P. et al. An extension of the flower pattern diagram for roll forming. Int. J. Adv. Manuf. Technol. 2016. Vol. 83. pp. 1683-1695. DOI: 10.1007/s00170-015-7667-0.

18. Shatalov R. L., Maksimov E. A. Analysis of efficiency of asymmetric rolling technology for increase of precision of rolled strips. Metallurg. 2016. No. 7. pp. 80-84.

19. Weiye Chen, Jinmao Jiang, Dayong Li, Tianxia Zou, Yinghong Peng. Flower pattern and roll positioning design for the cage roll forming process of ERW pipes. Journal of Materials Processing Technology. 2019. Vol. 264. pp. 295-312. DOI: 10.1016/j.jmatprotec.2018.09.007.

20. Han S.-W., Park Y. C., Kim H.-K., Kang S.-C. Effect of Strain Hardening on Increase in Collapse Pressure during the Manufacture of ERW Pipe. Appl. Sci. 2020. Vol. 10. pp. 5005. DOI: 10.3390/ app 10145005

21. Nguyen D. C., Efremov D. B. The method for determining the profile of large diameter pipes and the optimal technological mode during calibration-bending in the weld zone. IOP Conference Series: Materials Science and Engineering. 2020.Vol. 862. Iss. 3.

22. Iguchi K., Kuriyama Y., Moroi N., Hama T., Takuda H. Deformation behavior of high strength steel sheet during roll forming of electric resistance welded pipe. Steel Research International. 2012, Special issue. pp. 927-930.

23. Kolikov A. P., Romanenko V. P., Sheikh-Ali A. D. et al. Machines and equipment of tube production. Moscow: MISiS. 1998. $541 \mathrm{p}$.

24. Samusev S. V., Fadeev V. A. Study of the contact interaction of a strip with work rolls during continuous scelping of welded pipes in a TESA line. Chernye Metally. 2020. No. 2. pp. 41-46.

25. Samusev S. V., Fadeev V. A. Physical simulation of continuous forming process for longitudinal-welded tubes in the area of ERW mill open roll grooves. Izvestiys vysshikh uchebnykh zavedeniy. Chernaya metallurgiva. 2019. Vol. 62. No. 7. pp. 531-538. DOI: 10.17073/03680797-2019-7-531-538. 